\title{
Prediction of Crack Width Due to Corrosion of PC Tendon in Prestressed Concrete Structures
}

\author{
Maryoto, A. ${ }^{*}$ and Shimomura, T. ${ }^{2}$
}

\begin{abstract}
Corrosion expansion of prestressed concrete (PC) tendon affects mainly crack width on surface of concrete. This paper simulates corrosion expansion of PC tendon in concrete. Elastic expansion model is utilized for growing of corrosive product as a result of oxidation reaction on reinforcement. In reality, corrosive product penetrate freely into concrete. In order to cover this behavior, elastic expansion is then enhanced its capability in numerical simulation. Furthermore the proposed model used an apparent expansion is adopted to predict width of corrosion crack. Laboratory test is conducted to verify numerical result. Single and multi PC tendons embedded in concrete attacked by corrosion is investigated. Finally, prediction of crack width on surface of concrete due to corrosion of multi layers of PC tendons in the real pretensioned PC girder are conducted using the proposed model. The results show that corrosion crack width of the proposed model meets the real pretensioned.
\end{abstract}

Keywords: Corrosion expansion; corrosive product; elastic expansion; numerical simulation; PC tendon.

\section{Introduction}

Millions of concrete structures in the world are in service under corrosive environment. Eventhough concrete is designed using fly ash- based geopolymer concrete, steel reinforcement in concrete are attacked by corrosion due to seawater [1]. Propagation of corrosion crack width in pretensioned PC structures has a unique behavior. It differs from that of posttension PC and RC. In post tension PC, corrosion attacks firstly $\mathrm{PC}$ sheath. It protects $\mathrm{PC}$ tendon from corrosion. There is no reduction of prestressed forced due to initial period of corrosion on PC sheath. Both prestressed forced and corrosive product contribute on corrosion crack completely. Furthermore, steel bar in reinforced concrete is corroded by chloride ion directly. Crack width on surface of reinforced concrete is only produced by corrosive product. Unlike post tension PC structure, there is no contribution of prestressed force on crack width. On the other hand, when corrosion attack PC tendon of pre-tensioned PC structure, diameter of PC tendon and prestressed force decrease.

\footnotetext{
${ }^{1}$ Department of Civil Engineering, Jenderal Soedirman University Purwokerto, INDONESIA

2 Department of Civil and Environmental Engineering, Nagaoka University of Technology, JAPAN.

* Corresponding author; e-mail: agus_maryoto1971@yahoo.co.id
}

Note: Discussion is expected before November $1^{\text {st }} 2015$, and will be published in the "Civil Engineering Dimension" volume 18, number 1, March 2016.

Received 08 March 2015; revised 16 July 2015; accepted 10 August 2015
Corrosion crack on pre-tensioned PC structure is fully propagated by corrosive product and contributed partially by prestressed force. Figure 1 shows pre-tensioned PC beams of Urokozaki Bridge which had been in service for 35 years in the coastal area in Niigata, Japan. Corrosion cracks having great width are observed on the surface of concrete. The biggest crack width reached $11.5 \mathrm{~mm}$, which is around three times of PC tendon's diameter. In reality it is difficult to detect level of corrosion of PC tendon in concrete. On the other hand, crack width is easy to be measured from the surface of concrete cover. By converting crack width into level of corrosion, reduction of concrete capacity can be predicted. Therefore, repairing and handling the concrete structure can be done for safety and comfort of the people.

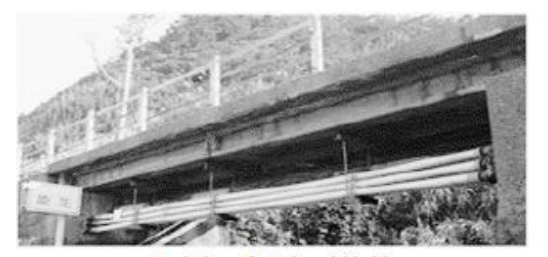

a. Existing of Urokazaki bridge

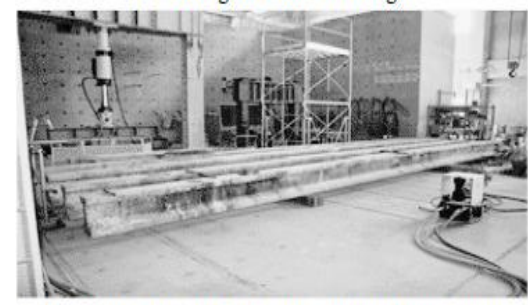

c. Beam of Urokazaki bridge after removed from existing

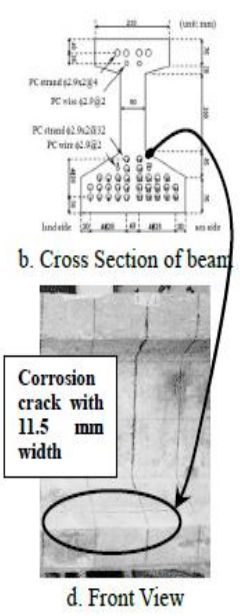

Figure 1. Beam of Urokozaki Bridge 
In the numerical modeling, corrosion expansion can be simulated using internal pressure, nodal displacement and thermal expansion. Internal pressure to express corrosion expansion was adopted to express expansion of corrosive product [2]. This method applied internal pressure to simulate corrosion expansion which pushes out concrete cover.

The second method which is nodal displacement was employed to investigate effect of uniform and nonuniform corrosion expansion in service life of concrete structures [3]. This method was adopted to simulate corrosive expansion by applying nodal displacement at the interface of steel and concrete. The third method is thermal expansion which represented corrosion expansion of steel bar in concrete. The thermal expansion method was executed in simulation by applying thermal load in the steel bar embedded in concrete. The investigation using thermal expansion was conducted by Maryoto et al. [4] and the result showed that the appearance of cover cracking on inner concrete by numerical modeling is faster than by experimental. Another result indicated that development of crack width on the concrete surface by simulation is also faster than the experimental work. This may be due to adoption of elastic expansion in the modeling. It is reasonable because penetration of corrosive product into ace around steel bar, pores, and cracks have not been considered yet. Consequently, expansion of corrosive product push out concrete cover directly without being followed its penetration in concrete. Finally, cracks of concrete cover in the simulation occurred earlier.

It is well known that corrosion expansion of steel bar in concrete is most affected by coefficient of rust expansion. The latest investigation was conducted to investigate it [5] and reported that coefficient of rust expansion had a range from 2.64 to 3.14. This work identified eight different locations in order to confirm those values. Furthermore, an identified location which was corresponding to coefficient of rust expansion due to corrosion of steel bar in concrete was electro-osmoses treated. As a result, that coefficient of rust expansion was 3.14. In addition, another important property of the rust [6] shows that the physical characteristic of the rust is like a gel.

Corrosion product penetrates into space around steel bar and porous zone of concrete in the range between ten to 20 micro meters [7]. At this stage, the rust flow is not restrained by concrete. Shortly after the pores around steel tendon are fully-filled, corrosion product will push out the concrete cover. Corrosion crack will be developed when the tensile stress due to pressure of the rust exceeds tensile strength of concrete. Unfortunately, volumes of rust infiltrated into cracks have not been taken into account.
This study tries to predict corrosion crack width due to expansion of corrosive product including their penetration into special interface between steel bar and concrete, pores, and crack in concrete. Corrosion of single and multi PC tendons are performed by numerical and experimental work. The experimental investigation is completed to clarify reliability the proposed model in order to predict crack width on concrete cover. The finite element program, [8] is employed to simulate corrosion crack in concrete member, in which a non-linear strain-softening behavior [9] is applied for cracks damage.

\section{Experimental Work Specimen}

\section{Single PC Tendon in Concrete}

Different prestressing forces are subjected on the specimens in order to clarify the effect of prestressed only on corrosion crack and reduction of prestressing stress due to reduction of PC tendon is neglected. This work uses PC tendons inserted in the posttensioned prestressed concrete. This method is conducted in order to avoid reducing prestressed force due to corrosion attack on PC tendons of pretension prestressed concrete. Figure 2 shows the specimen for corrosion of single PC tendon in concrete. Compressive stress by pre-stressing force in longitudinal direction is employed. Three specimens which are PC-0, PC-2 and PC-4, are tested. Number following the letter 'PC', which are 0,2 , and 4 , are to specify the compressive stress induced in the concrete in $\mathrm{N} / \mathrm{mm}^{2}$. Concrete cover is set as $15 \mathrm{~mm}$. Only the PC tendon $\varnothing 6 \mathrm{~mm}$ is artificially corroded. Table 1 shows the compressive stresses applied in the concrete. Each type comprises of one piece specimen.

PVC pipe is utilized as a sheath of post tensioned PC beam to protect steel bar $\varnothing 11 \mathrm{~mm}$ from corrosion. Prior to casting fresh concrete into the form, the PC tendon $\varnothing 6 \mathrm{~mm}$ of each beam is weighed to obtain the initial weight. Specimens are cured by covering with wet mattress for ten days. Compressive strength of concrete is tested by the cylindrical specimen of $\varnothing 100 \mathrm{~mm}$ and $200 \mathrm{~mm}$ height.

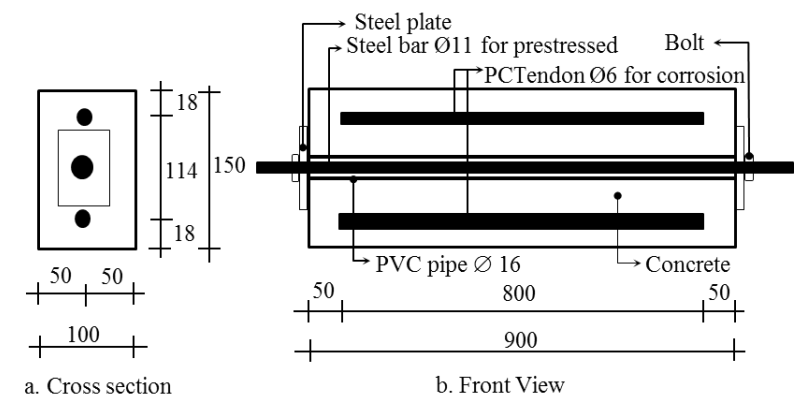

Figure 2. Specimen for Single PC Tendon 
Table 1. Compressive Stress

\begin{tabular}{ll}
\hline Name & Compressive stress $\left(\mathrm{N} / \mathrm{mm}^{2}\right)$ \\
\hline PC-0 & 0 \\
PC-2 & 2.33 \\
PC-4 & 4.73 \\
\hline
\end{tabular}

\section{Multi PC Tendons in concrete}

Figure 3 shows the dimension of RC specimens with six PC tendons embedded inside of concrete. The dimension of specimen is $100 \times 150 \times 1800 \mathrm{~mm}^{3}$. Thickness of concrete cover is $30 \mathrm{~mm}$ and spacing between PC tendons is $20 \mathrm{~mm}$ center to center. Only PC tendons with black color (Figure 3) are corroded by artificial corrosion test.

\section{Multi Layers of PC Tendons in Concrete}

Figure 4 shows cross section of pretensioned PC beam from real structure of Urokozaki Bridge, Japan. There are 34 pieces of PC tendons at bottom side and 6 pieces at top side embedded in concrete structure. The PC tendon diameter is $6 \mathrm{~mm}$ and the concrete cover is $27 \mathrm{~mm}$. Vertical and horizontal spacing between PC tendons is $22 \mathrm{~mm}$ and $14 \mathrm{~mm}$ center to center, respectively.

\section{Testing Procedures}

Compressive strength testing is performed using cylindrical specimen, diameter $100 \mathrm{~mm}$ and height $200 \mathrm{~mm}$ ten days of age. Mix proportion of concrete is shown in Table 2. Electrolytic corrosion test is conducted to produce rust in short time. Specimens are immersed in water containing $3 \%$ sodium chloride as an electrolyte. Figure 5 shows a schematic of the electrolytic corrosion test. Direct electric current is applied to promote corrosion process.

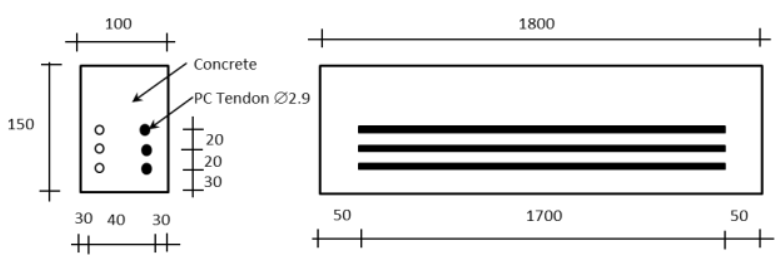

Figure 3. Specimen C3 for Multi PC Tendons

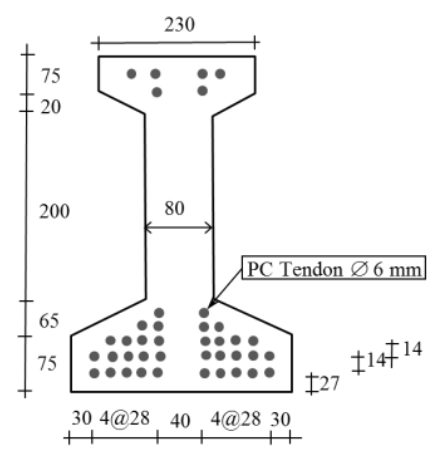

Figure 4. Cross Section of Pretensioned PC Beam
Table 2. Proportion of concrete mixture

\begin{tabular}{cccccccc}
\hline \multirow{2}{*}{$\begin{array}{c}\mathrm{G}_{\max } \\
(\mathrm{mm})\end{array}$} & $\begin{array}{c}\mathrm{W} / \mathrm{C} \\
(\%)\end{array}$ & $\begin{array}{c}\mathrm{s} / \mathrm{a} \\
(\%)\end{array}$ & \multicolumn{4}{c}{ wnit $\left(\mathrm{kg} / \mathrm{m}^{3}\right)$} \\
\hline 20 & 55 & 46 & 169 & 307 & 818 & 964 & 0.768 \\
\hline
\end{tabular}

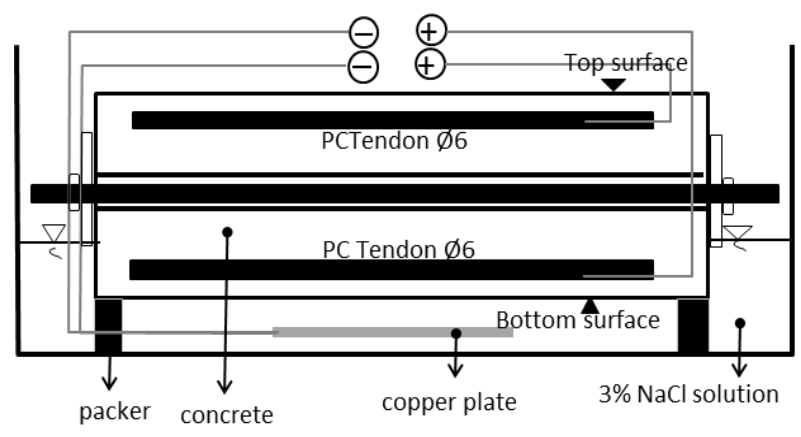

a. Corrosion test on single PC tendon

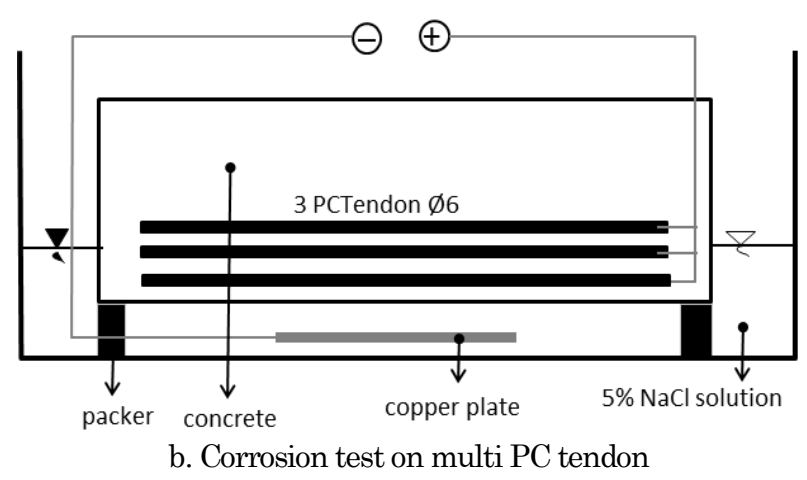

Figure 5. Schematic of Electrolytic Corrosion Test

In Table 2, $\mathrm{G}_{\max }$ is maximum size of aggregate, w/c is water/cement weight ratio, s/a is sand/total aggregate volume ratio, cement used is early strength type, additive type is water reducing agent. During the test, accumulative electric current and crack width are recorded. After the corrosion test is completed, the corroded PC tendons are taken out from concrete. Rust is then removed from PC tendons using a wire brush and finally immersed in $10 \%$ ammonium citrate solution for one day.

Occurrence of cracks is checked every day. When the first crack appears on the surface, the time of occurrence of the crack is recorded. The first crack is judged when crack width reached $0.01 \mathrm{~mm}$. Thereafter crack width is measured using manual scale at three points, which is in the middle of the beam, $100 \mathrm{~mm}$ to left side and right side from the mid-point. Average of those three crack widths is employed in the results and discussions. Electric current induced in corrosion test is recorded by the data logger every 30 minutes. Accumulative current $\left(\sum \mathrm{I} . \mathrm{T}\right)$ is calculated at the end of corrosion test. Amount of corroded PC tendon is estimated using Equation 1 based on Faraday`s law.

$\mathrm{W}_{\text {loss }}=\mathrm{a} \cdot \sum \mathrm{I} \cdot \mathrm{T}$ 
where, $\mathrm{W}_{\text {lossis }}$ the amount of corroded PC tendon (gr), $\alpha$ is coefficient of electrolytic corrosion (gr/A.hr), I is current (A), and T is time (hr). Coefficient of electrolytic corrosion is $1.0744 \mathrm{gr} / \mathrm{A} . \mathrm{hr}$. It is calculated according to

$\alpha=M /(z . F)$

where, $\mathrm{M}$ is the atomic mass of the metal $(\mathrm{Fe}=56$ $\mathrm{gr}), \mathrm{z}$ is the ionic valence of the metal $(\mathrm{Fe}=2)$ and $\mathrm{F}$ is Faradays constant (96,485 A.s).

Thereafter, mass loss of the PC tendon can be calculated by subtracting the initial weight from the weight after being corroded. Reduction of the PC tendon mass before ending of corrosion was calculated using interpolation based on accumulative current at the time.

\section{Numerical Simulation Modeling of Concrete}

Constitutive model of concrete in tension and compression is shown in Figures 6.a and b. The softening model according Figure 6.a is used for stress and strains relation [9]. The constant value $c_{1}$ is equal $0.31 . \varepsilon^{\mathrm{cr}}$ is the crack strain, and $\varepsilon_{\text {ult }}$ is the ultimate crack strain. The softening branch is defined in the Equation 1. Uniaxial tensile strength $\left(\mathrm{f}_{\mathrm{t}}\right)$, modulus of elasticity $(\mathrm{E})$ and fracture energy $\left(\mathrm{G}_{\mathrm{f}}\right)$ are estimated from compressive strength $\left(\mathbf{f}_{c}\right)$ and maximum aggregate size as stated in CEB model code [10]. Based on Figure 6.a, the ultimate crack strain is reached when the area of the tension softening is equal to $\mathrm{G}_{\mathrm{f}}$ divided by $\mathrm{h}$ and $\mathrm{h}$ is equal to $\sqrt[3]{V}$, where $\mathrm{h}$ is the crack bandwidth, $\mathrm{V}$ is the volume of the element. It can be defined that the crack bandwidth is a crack model as continuously smeared or parallel crack in the finite element. The material properties applied are presented in Table 3. The specimen is modeled using eight-node isoparimetric solid brick element and the meshing is shown in Figures 7 and 8. External compressive loads are loaded to the specimen in the longitudinal direction as shown in Figure 9 which is to simulate prestressed force by the PC tendon. The reduction of the prestressed due to corrosion is not considered.

$$
f_{t}=\frac{E}{1-x^{c_{1}}} \text { where } x=\frac{\varepsilon^{c r}}{\varepsilon_{u l t}}
$$

Crack width in the numerical simulation is measured in three points. This is same with the experimental work. First crack on the surface is identified using appearing of crack pattern on it. Widths of the cracks are calculated according to displacement between evaluated two nodes. Mass loss in simulation is computed according to Equations 2 and 3.

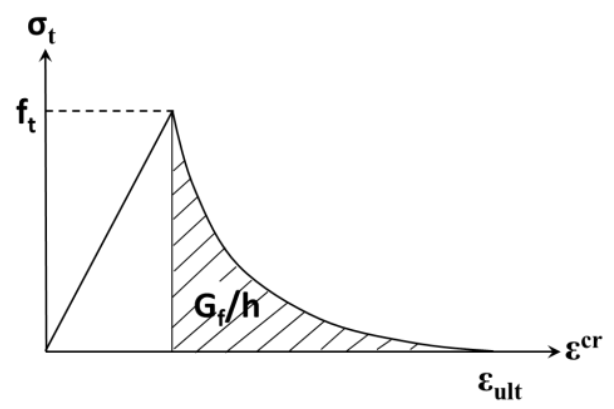

(a)

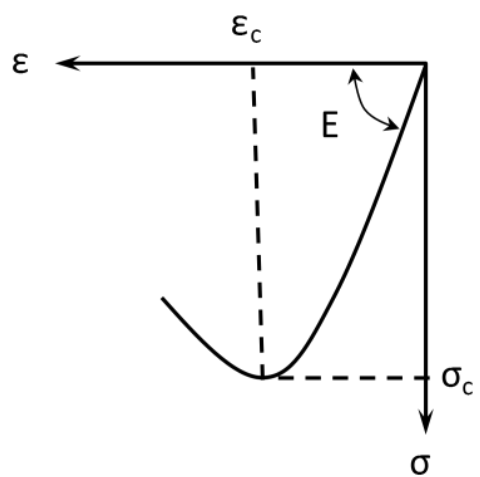

(b)

Figure 6. Constitutive Model of Concrete, a. in Tension; b. in Compression

Table 3. Properties of Concrete and Expansive Material

\begin{tabular}{lcc}
\hline \multirow{2}{*}{ Properties } & \multicolumn{2}{c}{ Material } \\
\cline { 2 - 3 } & Concrete & Expansive material \\
\hline Type & Isotropic & Orthotropic \\
Young Modulus, E (MPa) & 34070 & $\mathrm{X}, \mathrm{Y}, \mathrm{Z}$ axes $=1000$ \\
Poisson`s ratio, $\mathrm{v}$ & 0.2 & $\mathrm{X}, \mathrm{Y}$ axes $=0.49 ; \mathrm{Z}$ \\
& & axes $=10^{-12}$ \\
Tensile strength, $\mathrm{ft}_{\mathrm{t}}(\mathrm{MPa})$ & 3.01 & - \\
Fracture energy, $\mathrm{G}(\mathrm{N} / \mathrm{mm})$ & 0.1417 & - \\
Coefficient of thermal & - & $\mathrm{X}, \mathrm{Y}$ axes $=0.0012 ;$ \\
expansion, $\mathrm{a}$ & & $\mathrm{Z}$ axes $=10^{-12}$ \\
\hline
\end{tabular}

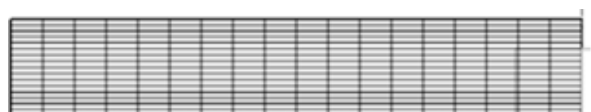

a. Front view

b. Side view

Figure 7. Single PC Tendon
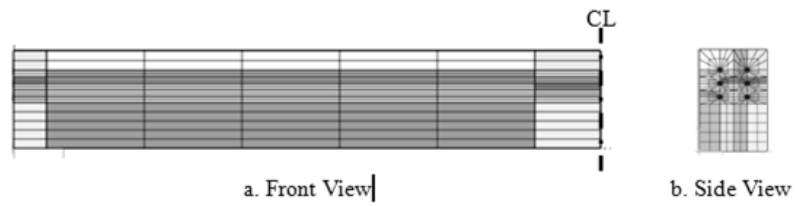

Figure 8. Multi PC Tendon

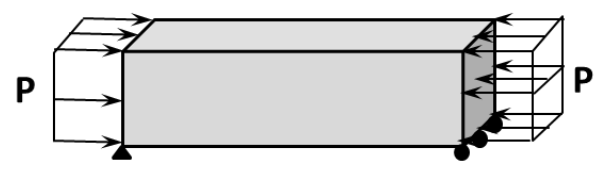

Figure 9. External Compressive Loads 


\section{Modeling of Corrosion Expansion of PC Tendon}

The three dimensional finite element program [8] is employed to simulate corrosion crack in concrete member, in which a non-linear strain-softening behavior in crack propagation [9] is considered. It is assumed that the PC tendon expands due to corrosion as shown in Figure10 and Equation 4.

$$
\frac{\pi\left(r_{0}+d r\right)^{2}-\pi \cdot r_{0}^{2}}{\gamma-1}=\pi \cdot r_{0}^{2}-\pi\left(r_{0}-r_{\text {loss }}\right)^{2}
$$

where, $d r$ is increment of radius of $\mathrm{PC}$ tendon due to corrosive expansion under unrestraint condition $(\mathrm{mm}), r_{\text {loss }}$ is loss of radius of PC tendon (mm), $r_{0}$ is original radius of $\mathrm{PC}$ tendon $(\mathrm{mm})$ and $\gamma$ is expansion coefficient of rust which is the ratio between volumes of corrosion product to the volume of PC tendon consumed in the corrosion process. The value of $\gamma$ was determined as 3.14 based on the experiment of Zhao et al. [5]. PC tendon is modeled as an elastic material.

Radius loss of PC tendon is converted into mass loss using Equation 5.

$$
W_{\text {loss }}=\frac{\left[\pi \cdot r_{0}^{2}-\pi\left(r_{0}-r_{\text {loss }}\right)^{2} \cdot \rho_{s}\right.}{2 \pi r}=\frac{\left[2 r_{0} \cdot r_{\text {loss }}-r_{\text {loss }}^{2}\right] \cdot \rho_{s}}{2 r_{0}}
$$

where, $W_{\text {loss }}$ is amount of corroded PC tendon in $\mathrm{gr} / \mathrm{mm}^{2}$ and $\rho_{s}$ is density of $\mathrm{PC}$ tendon which is equal to $7.85 \times 10^{-3} \mathrm{gr} / \mathrm{mm}^{3}$.

\section{Proposed Model to Predict Corrosion Crack}

Once the space around steel bar and porous zone are filled fully by corrosion product, induced stresses on the inner concrete cover by expansion of corrosion products is started. By the time corrosion product increase and stresses generated on concrete exceed tensile strength, micro crack occurs on the inner concrete cover. A part of corrosive product infiltrates in the inner of micro cracks while another part continues to generate stress on concrete cover. These processes are shown in Figure11.

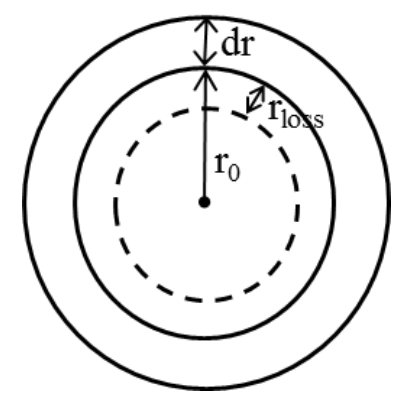

Figure10. Corrosive Expansion in Cross Section of PC Tendon

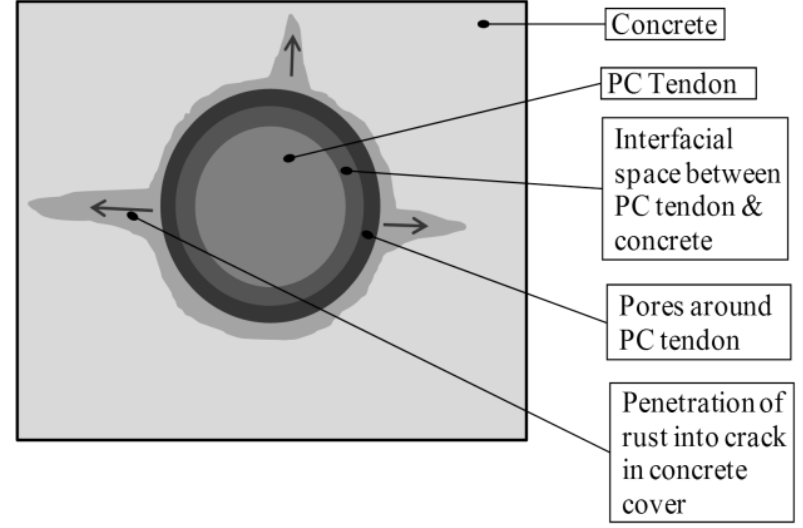

Figure 11. Process of Penetration of Corrosion Product into Concrete

The expansion of corrosion product modeled using elastic expansion in numerical simulation does not cover the penetration of corrosion product in concrete. To minimize this phenomenon, an apparent expansion model showed in Equations 6 and 7 are proposed to correlate strain of corrosion expansion as a function of amount of corroded steel bar.

$$
\begin{aligned}
& \varepsilon_{\text {exp }}=\sqrt{1+W_{\text {loss,app }} \frac{2(\gamma-1)}{r_{0} \rho_{s}}}-1 \\
& W_{\text {loss,app }}=\left(W_{\text {loss }}\left(1-\exp \left(-A * W_{\text {loss }}\right)\right)\right) * B
\end{aligned}
$$

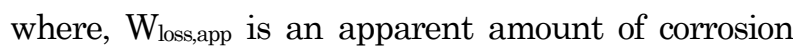
which is used in the proposed model $\left(\mathrm{gr} / \mathrm{mm}^{2}\right), \varepsilon_{\text {exp }}$ is expansive strain. The "A" and "B" are constants which are obtained based on experimental result.

\section{Application of the Proposed Model to Corrosion Crack in Actual Prestressed Girder}

This section explains how to apply the proposed model to real pretension PC member with multi PC tendons of Urokozaki Bridge which had been in service for 35 years in the coastal area in Niigata, Japan. Figure 12.a shows the real cross section of the girder of Urokozaki Bridge. In this study, only corrosion crack on the bottom flange is considered. PC tendon denoted with circular shape is classified into the first layer, triangular shape is the second layer and rectangular shape is the third layer. In general, corrosion on PC tendon protected by thick cover of concrete is slower than PC tendon protected by thin cover of concrete. Considering this, following assumptions are made in:

1. Corrosion level of PC tendon in the second layer is $50 \%$ of that in the first layer.

2. Corrosion level of PC tendon in the third layer is $25 \%$ of that in the first layer. 


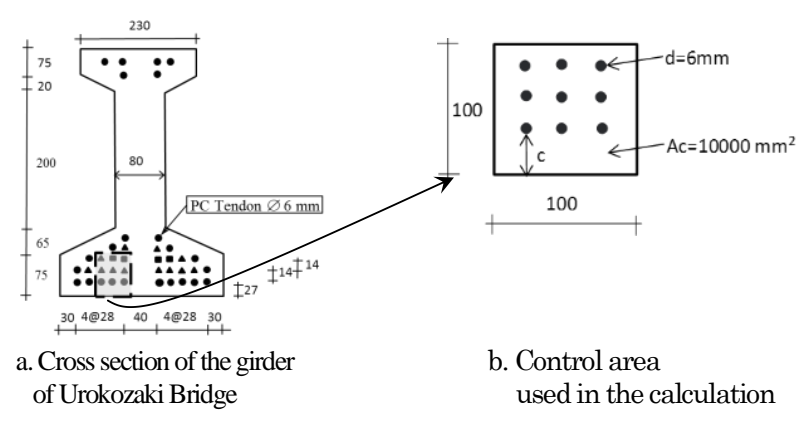

Figure 12. Parameters of the Enhanced Model For Girder of Urokozaki Bridge

Since the cross sectional area of the objective beam is greater than $10000 \mathrm{~mm}^{2}$, the model was applied to the control area of $100 \mathrm{~mm} \mathrm{x} 100 \mathrm{~mm}$, which involves nine PC tendons inside as shown in Figure 12.b.

\section{Results and Discussions}

\section{Specimen with Single PC Tendon in Concrete}

Based on Equations 6 and 7, the constants A and B applied in the proposed model are 0.06 and 1 which are attained based on experimental result. Figure 13.a shows experimental result which relates crack width as function of corroded PC tendon in concrete. The result indicates that before first crack occur on the surface of concrete, some corrosion products infiltrate into concrete. Figure 13.b shows relationship between crack width and corroded PC tendon as a result of elastic model and the proposed model. According the Figures, the propagation of crack width in the elastic model is faster than the proposed model because the elastic model does not simulate penetration of corrosion product into concrete. Penetration of corrosion product into concrete is well covered by the proposed model, as a consequence crack width on surface of concrete run slower. The weights of these infiltrations are nearly the same with the experimental result. Another important thing based on Figure 13 shows that the difference of crack width between PC-0, PC- 2 , and PC- 4 is very small. It also indicates that effect of prestressed on corrosion crack is not significant. Appearance of the first crack on surface of concrete and propagation of crack width of the proposed model has a good agreement to the experimental one. Crack is taken place at the center and parallel with the corroded PC tendon as shown in Figure 14.

In order to simplify the problem in prediction of corrosion crack in general structure, unit area of concrete is defined $100 \mathrm{~mm} \times 100 \mathrm{~mm}$ or $10000 \mathrm{~mm}^{2}$. Cross sectional area of PC tendon included in the unit area of concrete is taken into account in determination of "B". Cross section area of PC tendon $\left(A_{s}\right)$ and unit area of concrete $\left(A_{c}\right)$ is shown in Figure 15. There are two values of concrete cover which are horizontal $\left(\mathrm{ch}_{\mathrm{h}}\right)$ and vertical concrete cover $\left(\mathrm{c}_{\mathrm{v}}\right)$, the shorter one is adopted as "c", and $\mathrm{d}$ is diameter of steel bar.

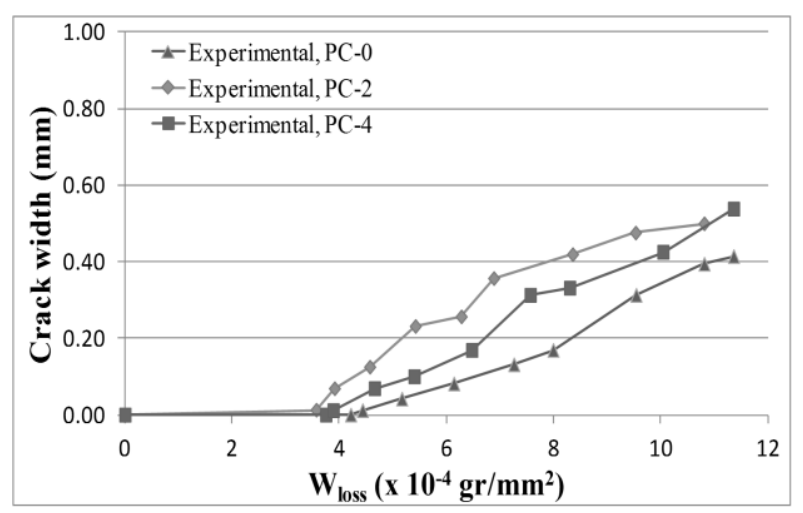

a. experimental result

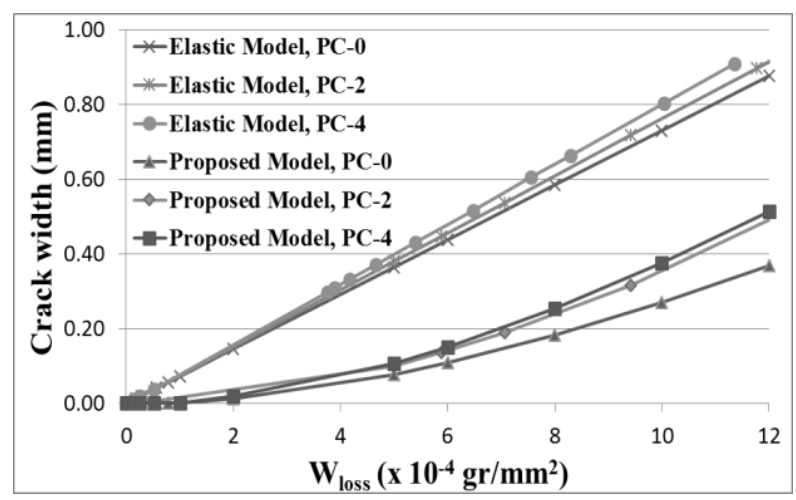

b. the elastic and proposed model

Figure 13. Crack Width on Specimen with Single PC Tendon in Concrete

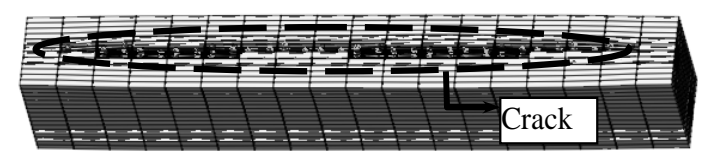

a. Numerical result of PC-4

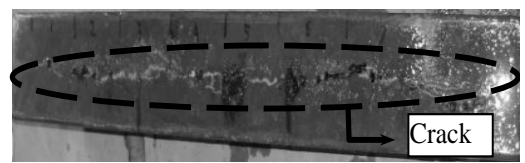

b. Experimental result of PC-4

Figure 14. Crack on Surface of Concrete Cover

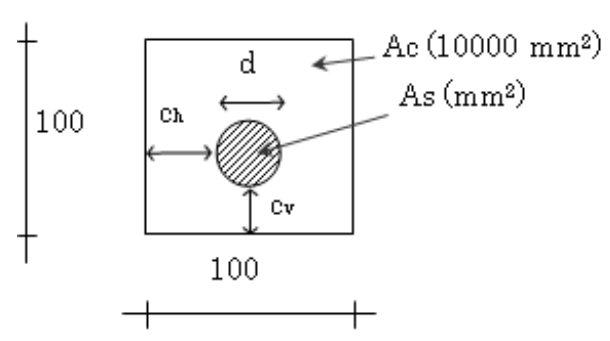

Figure 15. Unit Area of Concrete in Model 
Based on Figure 13.a, an empirical equation to determine parameter "A" in Equation 7 is proposed in Equation 8.

$$
A=0.15 * \frac{d}{c}
$$

where, $\mathrm{d}$ is diameter of PC tendon and $\mathrm{c}$ is concrete cover.

Diameter of PC tendon and thickness of concrete cover are included Equation 8 because they have impacts in generation of crack on the surface of concrete. An empirical equation to determine parameter "B" in Equation 7 is proposed as following, Equation 9:

$$
B=\frac{1}{0.0018 * \frac{A_{c}}{A_{s}}}
$$

where $\mathrm{A}_{\mathrm{s}}$ is cross sectional area of PC tendon and $\mathrm{A}_{c}$ is unit area of concrete.

By substituting the proposed empirical equation to determine "A" and "B" into Equation 8, following Equation 10 is achieved.

$$
W_{\text {loss }, a p p}=\left(W_{\text {loss }}\left(1-\exp \left(-0.15 * W_{\text {loss }}\right)\right)\right) * \frac{1}{\frac{0.0018 * A_{c}}{A_{s}}}
$$

\section{Specimen with Multi PC Tendons in Concrete}

Values of $c, d, A_{s}$ and $A_{c}$ used in the calculation are shown in Table 4. By substituting those values into Equation 9 and 4, relationship between $\mathrm{W}_{\text {loss }}$ and total crack width is found as shown in Figure 16.

Figure 16 shows the experimental and the proposed model's result of total crack width. The proposed model can simulate retardation of cracking due to penetration of corrosive product very well. Crack on the concrete surface of the experimental specimen started when value of the corrosion level reach 18.10 $4 \mathrm{gr} / \mathrm{mm}^{2}$ but the proposed model predicted crack began when the value of the corrosion level is about $5.10^{-4} \mathrm{gr} / \mathrm{mm}^{2}$. This corrosion level produces very small width of corrosion crack, and it is very difficult to be detected by eyes. When the corrosion level reach more than $18.10^{-4} \mathrm{gr} / \mathrm{mm}^{2}$ the crack propagation between the experimental result and the proposed model has similar tendency.

Table 4. Constants used in the Proposed Model

\begin{tabular}{ccccc}
\hline \multirow{2}{*}{ Specimen } & \multicolumn{4}{c}{ Constant } \\
\cline { 2 - 5 } & $\mathrm{c}(\mathrm{mm})$ & $\mathrm{d}(\mathrm{mm})$ & $\mathrm{A}_{\mathrm{s}}\left(\mathrm{mm}^{2}\right)$ & $\mathrm{A}_{\mathrm{c}}\left(\mathrm{mm}^{2}\right)$ \\
\hline $\mathrm{C}-3$ & 27 & 6 & 85 & 10000 \\
\hline
\end{tabular}

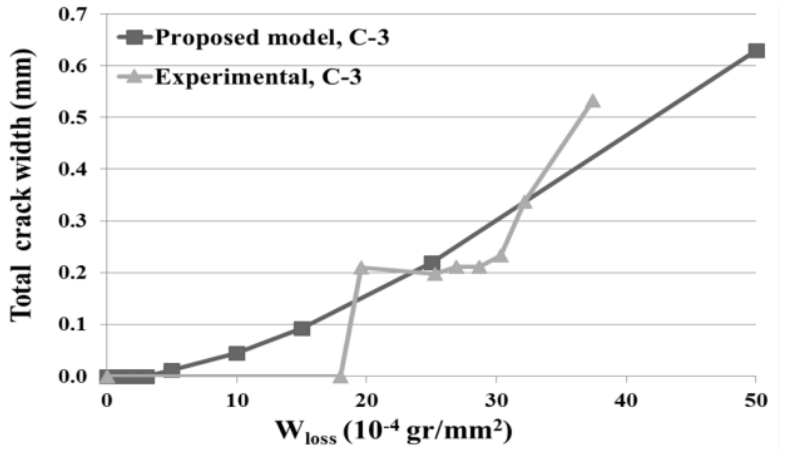

Figure 16. Crack Width on Specimen with Multi PC Tendon in Concrete

\section{Specimen with Multi Layers PC Tendons in Concrete}

Quantity, diameter and cross sectional area of PC tendon at each layer and cross sectional area of concrete based on Figure 10.b are shown in Table 5 . Substituting values in Table 5 into Equations 10 and 6 , corrosion crack width on the surface of the girder of Urokozaki Bridge as a function of amount of corrosion can be presented as shown in Figure 17.

Figure 16 shows that predictions of crack width on the surface by the proposed model with nine pieces of corroded PC tendons meet the experimental results, not only the occurrence of first crack but also the crack opening. It may be because penetration of corrosive product into concrete is already covered by the numerical simulation.

\begin{tabular}{|c|c|c|c|c|c|}
\hline Layer & $\begin{array}{l}\text { Quantity } \\
\text { of PC } \\
\text { tendons }\end{array}$ & $\begin{array}{c}\text { Concrete } \\
\text { cover, c } \\
(\mathrm{mm})\end{array}$ & $\begin{array}{l}\text { Diameter, } \\
\text { d (mm) }\end{array}$ & $\begin{array}{c}\text { Area of } \\
\text { corroded PC } \\
\text { tendon, } \mathrm{A}_{\mathrm{s}} \\
\left(\mathrm{mm}^{2}\right)\end{array}$ & $\begin{array}{l}\text { Area of } \\
\text { concrete, } \\
\mathrm{A}_{\mathrm{c}}\left(\mathrm{mm}^{2}\right)\end{array}$ \\
\hline $\mathrm{I}$ & 3 & 27 & 6 & $\begin{array}{c}3 * \Pi^{*} 3^{2 *} 1= \\
85\end{array}$ & $=100 \times 100$ \\
\hline II & 3 & 47 & 6 & $\begin{array}{c}3^{*} \Pi^{*} 3^{2 *} 0.5 \\
=42\end{array}$ & \\
\hline III & 3 & 67 & 6 & $\begin{array}{c}3^{*} \Pi^{*} 3^{2 *} 0.25 \\
=21\end{array}$ & \\
\hline \multicolumn{4}{|c|}{ Total area $=$} & 148 & 10000 \\
\hline
\end{tabular}

Table 5. Constants of Proposed Model for Multi Layers PC Tendons in Concrete

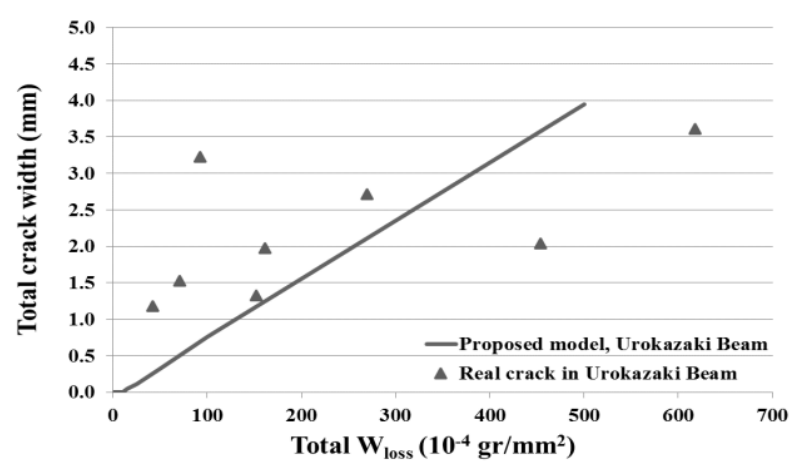

Figure 17. Total Crack Width in the Girder of Urokozaki Bridge 
After the real beam is cut, disparity of corrosion level among the PC tendons is very large. Consequently, amount of corrosive product penetrating into concrete is reduced as shown in Figure 18.a. Control area of Figure 18.b shows that the numbers of heavily corroded PC tendons are not nine pieces but only four pieces. In Figure 18.b, the heavily corroded $\mathrm{PC}$ tendons are indicated by black color.

In the control area, two PC tendons in the first layer, one PC tendon in the second layer and one PC tendon in the third layer are heavily corroded. Table 6 shows the constants of the model which are adjusted based on the observed corrosion. Using these values, relationship between total crack width and total amount of corrosion of PC tendon is obtained as shown in Figure19. It can be seen that the result of the proposed model using the modified parameter agrees very well with the measured result. The initial crack and crack propagation of the proposed model is closer to the real crack on Urokozaki beam.
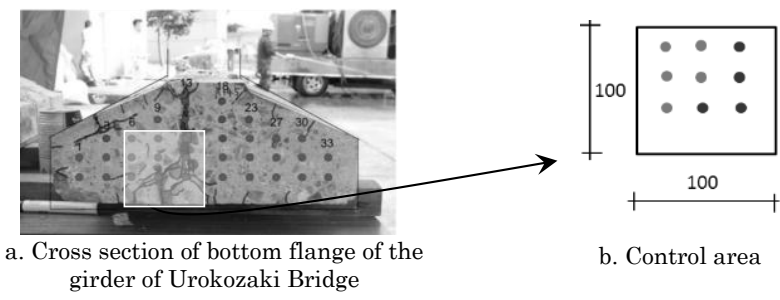

Figure 18. Distribution of Corroded PC Tendons in the Girder of Urokozaki Bridge

Table 6. Modified Parameters of the Proposed Model for Girder of Urokozaki Bridge

\begin{tabular}{|c|c|c|c|c|c|}
\hline Layer & $\begin{array}{l}\text { Quantity } \\
\text { of PC } \\
\text { tendons }\end{array}$ & $\begin{array}{c}\text { Concrete } \\
\text { cover, c } \\
(\mathrm{mm})\end{array}$ & $\begin{array}{l}\text { Diameter, } \\
\text { d (mm) }\end{array}$ & $\begin{array}{c}\text { Area of } \\
\text { corroded } \\
\text { PC tendon, } \\
\mathrm{A}_{\mathrm{s}}\left(\mathrm{mm}^{2}\right)\end{array}$ & $\begin{array}{c}\text { Area of } \\
\text { concrete, } \\
\mathrm{A}_{\mathrm{c}}\left(\mathrm{mm}^{2}\right)\end{array}$ \\
\hline $\mathrm{I}$ & 2 & 27 & 6 & $\begin{array}{c}2 * \Pi^{*} 3^{2 *} 1= \\
57\end{array}$ & $\begin{array}{l}=100 \mathrm{x} \\
100=\end{array}$ \\
\hline II & 1 & 47 & 6 & $\begin{array}{c}1^{*} \Pi^{*} 3^{2 *} 0.5 \\
=14\end{array}$ & \\
\hline III & 1 & 67 & 6 & $\begin{array}{c}1^{*} \Pi^{*} 3^{2 *} 0.25 \\
=7\end{array}$ & \\
\hline \multicolumn{3}{|c|}{ Total area = } & & 78 & 10000 \\
\hline
\end{tabular}

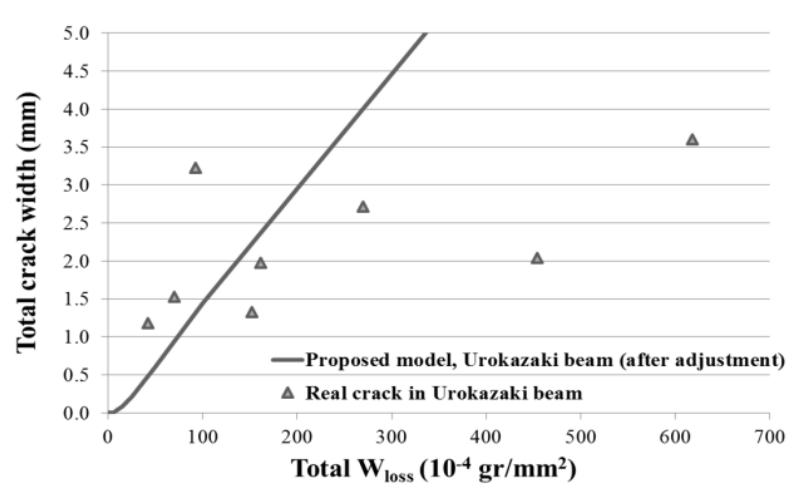

Figure 19. Total Crack Width of the Girder of Urokozaki Bridge based on Real Corrosion on PC Tendon

\section{Conclusions}

According to the results of the numerical simulation with enhancement of the model and experimental investigation on corrosion crack in pretensioned PC structures, following conclusions are obtained.

1. The proposed model which is numerical simulation with enhancement of elastic expansion can predict crack width on surface of pretensioned PC structures due to corrosion of multi layers of PC tendons.

2. Accuracy prediction of crack in concrete with multi layers of PC tendons is influenced by how many PC tendons are really attacked by corrosion.

\section{Acknowledgments}

The authors would like to thank the concrete laboratory of Nagaoka University of Technology, Japan for the support. A financial support to continue this work from Indonesian government is also greatly acknowledged.

\section{References}

1. Astutiningsih, S., Rustandi, A., and Noermalasari, D., Corrosion of Steel Reinforcements in Fly Ash and Kaolin-based Geopolymer Concrete Immersed in Distilled Water and ASTM Seawater, Civil Engineering Dimension, 15(2), 2013, pp. 89-95.

2. Du, Y.G., Chan, A.H.C., and Clark, L.A., Finite Element Analysis of the Effect of Radial Expansion of Corroded Reinforcement, Computer and Structures, 84, 2006, pp. 917-929.

3. Zhao, Y., Karimi, A.R., Wong, H.S, Hu, B., Buenfield, N.R., and Jin, W., Comparison of Uniform and Non-uniform Corrosion Induced Damage in Reinforced Concrete based on a Gaussian Description of the Corrosion Layer, Corrosion Science, 53, 2011, pp. 2803-2814.

4. Maryoto, A., Kitazono, Y., and Shimomura, T., Numerical Simulation of Corrosion Crack in Reinforced Concrete (RC) and Prestressed Concrete (PC) Member, Proceeding of JSCE, Niigata Conference - Japan, 2012, pp. 378-381.

5. Zhao, Y., Ren, H., Dai H., and Jin, W., Composition and Expansion Coefficient of Rust based on X-ray Diffraction and Thermal Analysis, Corrosion Science, 53, 2011, pp. 1646-1658.

6. Andrade, C., Tavares, F., Toro, L., and Fullea, J., Observation on the Morphology of Oxide Formation due to Reinforcement Corrosion, RILEM, 2011, pp. 179-193. 
7. Thoft, P.C., Stochastic Modeling of the Crack Initiation Time for Reinforced Concrete Structures, Structures Congress, Philadelphia, 2000.

8. Diana, User's Manual, Release 9.4.4, TNO DIANA, BV, Delft, The Netherlands, 2010.
9. Reinhardt, H.W., Fracture Mechanics of an Elastic Softening Material like Concrete, Heron 29(2), 1984.

10. Comite Euro-International du Beton-Federation Internationale de la Precontrinte, CEB-FIP Model Code, Thomas Telford Ltd, London, 1990. 